\title{
Evolução do modo de regulação escolar e reestruturação da função de diretor de escola
}

\author{
The evolution of the way of the school regulation
} and reestruction of the principle's function

Branka Cattonar ${ }^{1}$

\begin{abstract}
Resumo
Nos dez últimos anos, os sistemas educacionais de todas as províncias do Canadá sofreram transformações importantes no que diz respeito ao seu modo de regulação, o que repercutiu nas condições e no teor do trabalho dos atores escolares. Nosso artigo propõe-se a estudar os efeitos dessas transformações sobre o trabalho dos diretores de escola. Como eles as percebem? Como vivem, concebem e exercem hoje a sua função? Tentaremos responder a essas perguntas com base nos resultados de uma pesquisa realizada em 2005, por meio de questionários, junto a 2.144 diretores de escolas primárias e secundárias de todo o Canadá. A pesquisa revela notadamente que a maioria dos diretores tem uma visão relativamente matizada em relação aos impactos das transformações escolares, mostrando ao mesmo tempo que seu trabalho envolve o exercício de grande número de responsabilidades e parece proporcionar-lhes satisfação profissional no tocante a vários aspectos.
\end{abstract}

Palavras-chave: Diretor de Escola; Concepções do Trabalho; Transformações Escolares

\section{Abstract}

These last ten years, the educational systems of the provinces in Canada knew several important changes in their mode of regulation which have effects on the conditions and the content of the work of the school actors. Our article intends studying their effects on the work of the principals of schools: How do they feel the recent school evolutions? How do they live, do they conceive and do they exercise their work today? We shall try to answer these questions on base of the results of a survey by questionnaire realized in 2005 with 2144 principals of elementary and secondary schools in the whole of Canada. The survey shows that most of the principals have a qualified vision of the impacts of the school evolutions, that their work implies on the exercise of a multitude of responsibilities and that it appears to bring them a professional satisfaction under numerous aspects.

Keywords: Principal; Work's Conceptions; School Evolutions

1 Pesquisadora do Labriprof/CRIFPE, Universidade de Montreal (Canadá). cattonarbranka@yahoo.fr.m 


\section{EVOLUÇÃo dO MOdO DE REGULAÇÃo ESCOLAR E REDEFINIÇÃo NORMATIVA DO PAPEL DOS DIRETORES DE ESCOLA}

Nos dez últimos anos, os sistemas educacionais de todas as províncias do Canadá passaram por transformações importantes no que diz respeito ao seu modo de regulação. Entretanto, excetuando as políticas e formas de evolução escolar específicas a cada província, determinadas tendências são comuns a todas as regiões. ${ }^{2}$ Nesse sentido, Lessard, Brassard e Grimmet indicam a existência de uma "estratégia pancanadense" de harmonização da educação no país, estratégia essa centrada na obrigação de produzir resultados e na imputabilidade dos atores do mundo da educação, e cuja ênfase é a produção de resultados quantificados e de indicadores de desempenho escolar (LESSARD; BRASSARD, 2007; LESSARD; GRIMMETT, 2004). De modo mais específico, Lessard et al. apontam duas transformações mais importantes na forma de governança educacional no Canadá. A primeira é o reforço da autoridade central do sistema educacional, que se reflete em diversas medidas, tais como maior controle da qualidade, o desenvolvimento de avaliações padronizadas, maior centralização do currículo e do financiamento e a criação de padrões de desempenho. A segunda é a intensificação do "eixo horizontal da governança", que apresenta relativo movimento de descentralização dos poderes em direção aos estabelecimentos de ensino e se traduz no incentivo à mobilização dos atores escolares locais, na elaboração de "planos de desempenho" por cada escola, no desenvolvimento de uma lógica da competição entre os estabelecimentos escolares etc. (LESSARD; BRASSARD, 2007; LESSARD; GRIMMETT, 2004). ${ }^{3}$

2 O Canadá é um Estado federal composto de dez províncias e três territórios. Como indicam Bernard e Saint-Arnaud (2004), as províncias canadenses se caracterizam por possuírem políticas sociais específicas e por uma articulação peculiar entre o Estado, o mercado e a família, embora estejam ligadas ao mesmo regime de bem-estar social do tipo liberal. A educação primária e secundária é de competência provincial (estadual), e a administração escolar baseia-se numa estrutura composta de três níveis: as autoridades provincias (Parlamento Provincial ou Ministério da Educação), as autoridades intermediárias (Comissões Escolares ou Distritos Escolares, que são entidades administradas por um conselho de comissários eleitos pela população e responsáveis por um determinado território) e os estabelecimentos escolares (LESSARD; BRASSARD, 2007; LESSARD; GRIMMET, 2004).

3 Essas tendências também são notadas, em diferentes graus, em numerosos países europeus, onde assistimos ao aumento dos "Estados avaliadores", os quais tendem a assumir o controle das orientações gerais do sistema educacional (definição das missões e dos critérios de operacionalização dos "resultados" do sistema), ao mesmo tempo em que delegam aos atores a gestão dos meios (MAROY; DUPRIEZ, 2000). 
Essas transformações na regulação do sistema educacional são acompanhadas de uma redefinição normativa da concepção e do papel do estabelecimento escolar. De acordo com Lessard e Brassard (2007), a concepção atualmente dominante no Canadá é a do estabelecimento escolar enquanto "escola comunitária" que deve, ao mesmo tempo, formar uma verdadeira "comunidade educativa" e criar laços com a comunidade à qual atende. Seguindo essa lógica, a mobilização dos atores locais passa a ser fortemente incentivada: exige-se que os docentes trabalhem em equipes e atribui-se aos pais dos alunos um papel relevante no funcionamento do sistema educacional (especialmente através de sua participação nos Conselhos Escolares). Essa tendência é paralela a uma responsabilização maior dos estabelecimentos em relação ao sucesso escolar dos alunos, no âmbito de uma "autonomização balizada" do pessoal docente e administrativo. De fato, embora a autonomia profissional do pessoal docente seja valorizada na retórica política, ela continua sendo, na verdade, balizada por currículos centralizados e por avaliações padronizadas de caráter público. Conforme Ben Jaafar e Anderson (2004), a escola tornou-se assim uma "unidade de prestação de contas", e é considerada publicamente responsável pelo desempenho dos alunos. Simultaneamente, assistimos a diversas formas de "dessetorização" da educação que proporcionam aos pais maior liberdade na escolha da escola de seus filhos, instauram uma forma de concorrência entre as escolas e obrigam-nas a se posicionarem nesse "quase-mercado escolar" (LESSARD; BRASSARD, 2007). Em suma, o estabelecimento escolar é visto cada vez mais como um lugar onde os diversos atores não só devem se mobilizar e trabalhar juntos para produzir bons resultados, mas também são considerados publicamente responsáveis pelo desempenho dos alunos.

Essa redefinição do estabelecimento escolar, que lhe confere importância maior na implementação das políticas escolares e mais responsabilidade no tocante à qualidade e à eficácia do ensino, é acompanhada de uma redefinição institucional, normativa e prescritiva do papel e do trabalho do pessoal da educação. No que diz respeito aos diretores de escola, vários autores afirmam que novas prescrições institucionais impelem-nos a tornarem-se "líderes pedagógicos" responsáveis pela coordenação da atividade educativa em sua escola e pela condução das reformas escolares através da mobilização de sua equipe educativa (BERGERON; MASSÉ; RATHÉ, 2005; BRASSARD; CLOUTIER; DE SAEDELEER; CORRIVEAU; FORTIN; GÉLINAS; SAVOIE-ZAJC, 2004; CORRIVEAU, 2004). Na Europa, observam-se 
tendências semelhantes, e vários estudos mostram que os diretores não devem mais ser somente administradores e gestores, mas também “animadores pedagógicos", iniciadores da política pedagógica de sua escola e "agentes de mudança" do sistema educacional (DUTERCQ, 2006). Na Comunidade Francesa da Bélgica, Dupriez (2002; 2005) mostra que, seguindo a lógica de condução do sistema educacional por meio de resultados, as recentes políticas escolares valorizam um novo modelo ideal de "estabelecimento mobilizado", no qual se espera que os diversos atores construam projetos coletivamente, a fim de produzir um ensino de qualidade adaptado às especificidades de seu ambiente. Também ocorre uma redefiniçao do papel do diretor de escola: ele é chamado a tornar-se um "animador pedagógico", e deve não somente ser capaz de gerir pessoas e recursos, mas também se envolver na condução do projeto pedagógico de sua escola e velar para que haja acordo entre os professores. Na França, Pelage $(1998 ; 2003)$ ressalta que o "chefe de estabelecimento", atualmente, deve tornar-se um ator dinâmico da transformação do sistema educacional, combinando várias competências: rigor administrativo e mobilização dos recursos humanos, eficiência gerencial e compromisso com os resultados, responsabilidades e inovações pedagógicas.

Lá, o papel do diretor é redefinido em torno da figura do "chefe de estabelecimento pedagogo", o qual deve apoiar a modernização do sistema educacional facilitando o surgimento de práticas pedagógicas inovadoras e incentivando a reflexão coletiva e o trabalho em equipe. Na Inglaterra, Osborn (2002) salienta que os diretores de escola são percebidos, agora, como "agentes de mudança" que devem se responsabilizar pela implantação das mudanças na escola, ao passo que, na década de 1980, os headteachers eram percebidos, primeiramente, como membros do pessoal docente cuja função principal era dirigir os outros docentes. Seu novo papel afasta-os então do ensino, dos alunos e dos docentes. De forma geral, Leclercq (2005) destaca que em vários países da Europa e da América do Norte a maior autonomia e responsabilização dos estabelecimentos escolares foram acompanhadas da redefinição da função de diretor de escola, o qual não é mais considerado como um simples administrador encarregado de observar os regulamentos, executar o orçamento e gerir o pessoal, mas simultaneamente como um gestor, um animador pedagógico e um iniciador, responsável pelos resultados que obtém junto a um grupo de pessoas que deve conhecer e coordenar.

Nesse contexto de transformação do modo de regulação do sistema educacional e de redefinição normativa do estabelecimento escolar, parece- 
nos importante identificar quais são seus efeitos reais sobre as condições e sobre o teor do trabalho dos diretores de escola: Como os diretores percebem as recentes transformações escolares? Como eles vivem, concebem e exercem hoje a sua função? São essas as perguntas às quais vamos tentar responder neste artigo, tomando como ponto de apoio os resultados de uma pesquisa realizada por meio de questionários junto a diretores de escolas primárias e secundárias de todo o Canadá. ${ }^{4}$

Num primeiro momento, faremos uma breve apresentação dessa pesquisa e falaremos da amostra e dos princípios que nortearam a análise estatística. Em seguida, exporemos os principais resultados obtidos, resultados que esclarecem, por um lado, a maneira como os diretores de escola vivem as recentes transformações do sistema educacional e, por outro lado, a maneira como eles concebem e dizem exercer seu trabalho, e procuraremos então captar as tensões entre o "trabalho real" e o "trabalho ideal". Veremos que a maioria dos diretores diz estar confrontada com numerosas transformações, cujos impactos são percebidos por eles de forma relativamente matizada. Veremos também que, segundo eles, o trabalho que realizam envolve inúmeras responsabilidades e papéis, e lhes proporciona satisfação profissional em numerosos aspectos. Concluiremos, então, emitindo algumas hipóteses sobre a maneira pela qual a evolução do modo de regulação ocasiona uma reestruturação da função de diretor no Canadá. Suporemos, em especial, que ela vem acompanhada de um maior envolvimento deles nas relações com o mundo fora da escola e na supervisão efetuada junto aos professores.

\section{A pesquisa}

A pesquisa através de questionários foi realizada em 2005, junto a 4.800 diretores, obedecendo a um plano de amostragem estratificada por província e nível de ensino. 2.144 diretores responderam, o que corresponde a uma taxa de respostas de 44,6\%. Entre estes, 63,1\% dirigem uma escola primária, 23,7\% uma escola secundária e 13,2\% uma escola

$4 \quad$ Essa pesquisa fazia parte de uma maior financiada pelo Conselho de Pesquisas em Ciências Humanas do Canadá e dirigida pelos professores François Larose (Universidade de Sherbrooke) e Claude Lessard (Universidade de Montreal). Ela foi realizada no âmbito de uma pesquisa subvencionada pelo Conselho de pesquisa em ciências humanas do Canadá (Grandes trabalhos de pesquisa concertados - Grands travaux de recherche concertés), sob a direção de J.-G. Blais, J. Bourque, F. Larose, C. Lessard, M. Tardif e A. Wright. 
"mista" (que oferece ao mesmo tempo ensino primário e secundário). A maioria trabalha em escola pública (90\%), e em regiões urbanas $(70 \%)$. Por fim, nossa amostra é composta de $25,5 \%$ de diretores provenientes de Ontário, 22,5\% das Pradarias, ${ }^{5}$ 19,6\% do Quebec, 15,4\% do das províncias do Atlântico, ${ }^{6} 14,4 \%$ da Colúmbia Britânica e 2,6\% dos Territórios. ${ }^{\top}$

O questionário continha 50 perguntas, pelas quais se procurava atingir vários objetivos: elaborar um retrato do perfil socioprofissional dos diretores, compreender seu percurso de inserção profissional, captar suas opiniões a respeito das mudanças ocorridas na escola, analisar sua relação com a função (tarefas realizadas, concepções ideais do trabalho e satisfação profissional) e descrever suas condições de trabalho (as características sociais e escolares dos alunos da escola que dirigem, as relações sociais no âmbito da escola e suas orientações educativas).

A análise dos dados assim recolhidos visa estudar a função de diretor a partir das representações subjetivas dos "chefes de estabelecimento", no que diz respeito ao seu próprio trabalho, sem perder de vista as condições objetivas nas quais se dão suas experiências profissionais. Ela segue uma perspectiva sociológica "construtivista" (CORCUFF, 1995) da identidade profissional, que considera essa mesma identidade como uma construção a um só tempo social e individual, resultado relativamente estável e evolutivo de um processo de socialização biográfico e relacional ligado ao contexto específico (sócio-histórico, educativo e profissional) no qual ele se insere (CATTONAR, 2001 e 2006a; DUBAR, 1996). Concretamente, através da análise estatística, procurou-se realizar uma "descrição compreensiva" da realidade atual da função de diretor, examinando a forma como suas percepções das mudanças escolares, suas concepções em relação à sua função, suas práticas e sua experiência variam, seja de acordo com seu perfil socioprofissional (gênero, idade, diploma etc.), seja de acordo com o seu contexto de trabalho (nível de ensino, localização urbana ou rural da escola, provínica, características dos alunos e do pessoal etc.). O objetivo final do nosso estudo é identificar tanto os

5 A região das Pradarias é composta pelas seguintes províncias: Alberta, Saskatchewan e Manitoba.

6 Na região do Atlântico estão Nova Escócia, Novo Brunswick, Terra Nova e Labrador, e a Ilha do Príncipe Eduardo.

7 A região dos Territórios compreende os Territórios do Noroeste, do Yukon e do Nunavut. 
princípios de unidade quanto os princípios de diferenciação dentro desse corpo profissional. Neste artigo, entretanto, daremos ênfase principalmente às percepções em relação à função e às experiências profissionais comuns a todas as pessoas questionadas.

\section{A percepção relativa às transformações ESCOLARES E Às SUAS REPERCUSSÕES}

Como podemos ver na Tabela 1 , a maioria dos diretores questionados estima que numerosas transformações tiveram efeitos importantes em sua escola. De modo mais específico, mais de $85 \%$ dos diretores julgam muito importante ou importante o impacto das mudanças de caráter pedagógico (a introdução de novas abordagens educativas e das tecnologias da informação e da comunicação) e das restrições orçamentárias (diminuição dos recursos humanos e outros). Várias mudanças no modo de regulação escolar também são apontadas pela maioria dos questionados, como, por exemplo, as novas políticas de imputabilidade $(79 \%$, se juntarmos as duas primeiras posições da escala), a nova divisão dos poderes entre as instâncias centrais e locais $(72,2 \%)$, a avaliação padronizada dos alunos $(71,7 \%)$ e a avaliação formal dos professores $(61,6 \%)$. Entretanto, somente 39,7\% dos diretores estimam ser importante o aumento da competição entre as escolas. ${ }^{8}$

8 As percepções relativas à importância das diversas mudanças estão correlacionadas positivamente entre si. Entre as mais fortes correlações, podemos apontar aquelas entre as novas políticas de imputabilidade, a avaliação padronizada dos alunos, a avaliação formal dos professores e a nova divisão dos poderes entre as instâncias centrais e locais. 


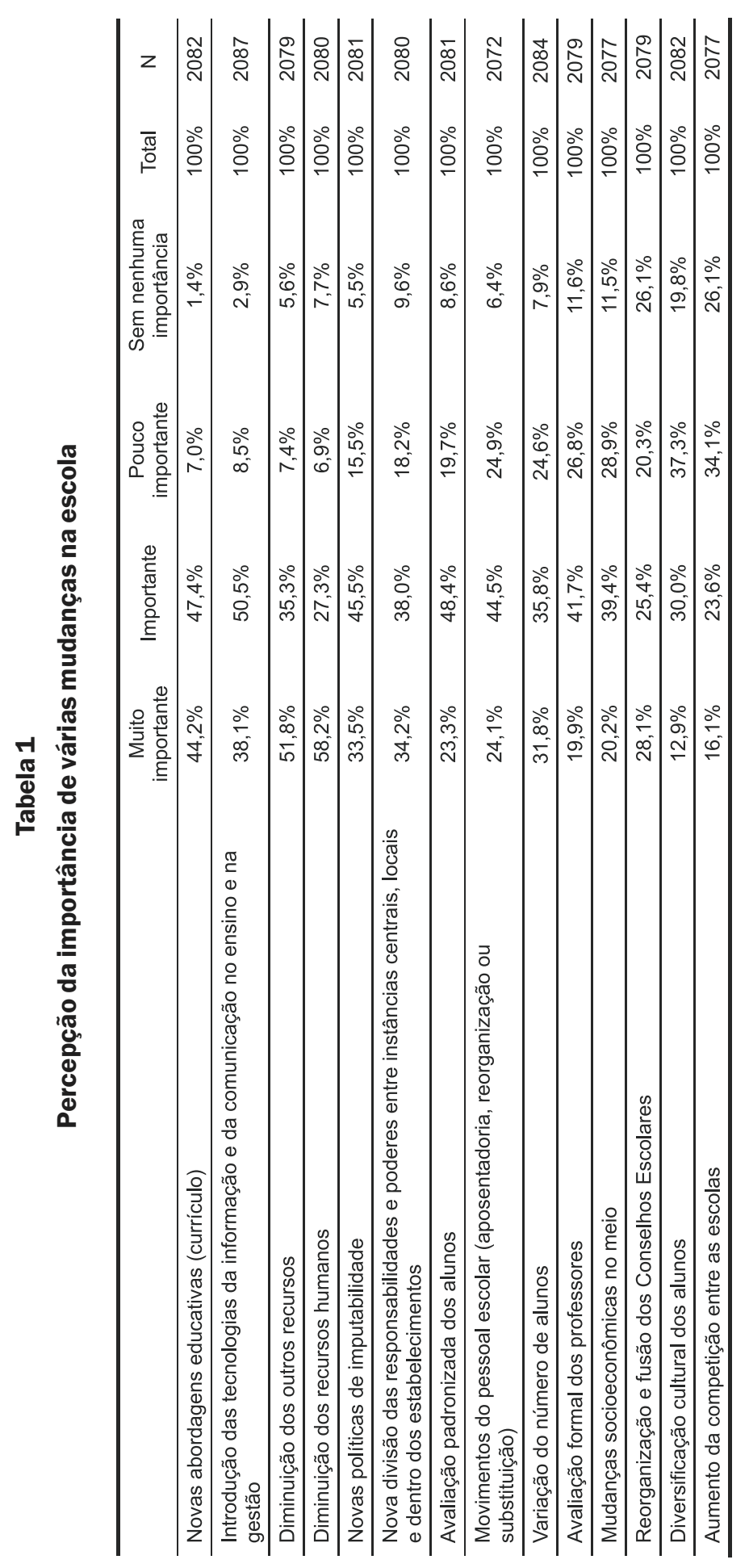

192 Educação em Revista, Belo Horizonte, v. 44. p. 185-208. dez. 2006 
Para os diretores, essas transformações têm numerosas conseqüências, tanto negativas quanto positivas ou "neutras", s sobre sua função e sua escola. Entre os principais efeitos negativos apontados, a maioria das pessoas questionadas evoca o aumento de sua carga de trabalho (96\%), o desenvolvimento de um clima de desconfiança nas escolas (66,7\%), a perda dos pontos de referência habituais $(62,6 \%)$, diminuição na qualidade dos serviços oferecidos aos alunos $(60,3 \%)$ e o desenvolvimento de um sentimento de ineficiência (58,5\%). A maioria dos diretores, entretanto, parece permanecer otimista, na medida em que pensam que tais transformações terão, no futuro, inúmeros efeitos positivos: sobre a aprendizagem dos alunos (81,7\%), sobre sua função de diretor $(74,4 \%)$, sobre a integração social dos alunos $(68,5 \%)$, sobre as relações com os pais $(67,7 \%)$, sobre a profissionalização dos professores $(67,4 \%)$, sobre o reconhecimento da missão da escola $(67,2 \%)$ e sobre a eficácia do sistema escolar $(66,9 \%)$. Esse otimismo poderia refletir certa adesão por parte dos diretores às transformações atuais. Poderia, também, ser atribuído a motivações profissionais específicas, distintas especialmente das dos professores. Vários estudos mostraram, assim, que os diretores gostam dos desafios trazidos pelas mudanças, e de se sentirem no "centro da ação", apesar da exigência e da complexidade da função que exercem (BARRÈRE, 2006; CORRIVEAU, 2004). No item a seguir, veremos que a maioria dos diretores valoriza seu papel de "agente da mudança". Poderíamos supor que essa atitude diante das transformações escolares é relativamente recente e traduz certa "interiorização" da atual exigência de se tornarem atores responsáveis pela transformação do sistema educacional. Um estudo realizado no início dos anos 1990, em todo o Canadá, mostra, no entanto, que os diretores tinham uma opinião negativa sobre as políticas governamentais (KING; PEART, 1992).

Nossa pesquisa mostra que os diretores evocam também vários efeitos que podem ser denominados de "neutros", como o desenvolvimento de novas capacidades de adaptação (92,1\%), aumento na demanda de capacitação e de acompanhamento institucional (81,6\%), consciência maior das relações com o meio no qual a escola está situada

9 Quatro perguntas foram feitas aos diretores para identificar suas percepções em relação a um grupo de trinta efeitos possíveis. 
$(80,1 \%)$ e uma modifição no seu modo de gestão $(79,6 \%) \cdot{ }^{10}$ Finalmente, a maioria dos diretores parece ter uma visão variada e matizada dos efeitos das transformações escolares em sua escola e em sua função. Suas percepções variam, entretanto, de acordo com as províncias onde trabalham, as quais sofreram efetivamente transformações específicas (LESSARD; BRASSARD, 2007; LESSARD; GRIMMETT, 2004). De maneira muito esquemática, os dados da pesquisa evidenciam que a presença de um "quase-mercado escolar" e de uma lógica da concorrência entre os estabelecimentos escolares é percebida muito mais pelos diretores de Alberta, do Quebec, da Colúmbia Britânica e de Ontário; o modo de governança centrado nos resultados, que se traduz em avaliações padronizadas (dos alunos e dos professores) e numa política de imputabidade, é mais notado em Alberta, em Ontário, na Colúmbia Britânica e nas províncias do Atlântico; a reorganização dos poderes entre os níveis centrais e locais é indicada muito mais no Quebec e nas províncias do Atlântico; enfim, o aumento da participação dos pais no sistema educacional é mais apontado nas Pradarias e nas províncias do Atlântico. Por outro lado, a pesquisa mostra que as percepções dos diretores em relação às transformações escolares diferem também, um pouco menos, no entanto, de acordo com outras variáveis contextuais, como o nível de ensino, o perfil da clientela escolar e a localização urbana ou rural da escola que dirigem. Assim, quanto mais eles dizem lidar com uma clientela escolar "difícil" (alunos tumultuosos, que chegam atrasados, são apáticos etc.), mais tendem a julgar importante o impacto das mudanças escolares, e a acreditar que elas tenham efeitos negativos. E são aqueles que dirigem escolas freqüentadas por alunos de origem social privilegiada (cuja renda familiar é alta) que mais tendem a julgar importante o aumento da competição entre as escolas de seu setor e o reforço na seleção dos alunos. Ocorre o mesmo com os diretores das escolas secundárias e urbanas.

10 As percepções em relação aos diversos efeitos das transformações ocorridas na escola estão, em sua maioria, correlacionadas entre si. Em especial, observa-se que quanto mais os diretores consideram que sua carga de trabalho aumentou, mais eles julgam importante as seguintes transformações: modificação em sua forma de gestão, diminuição dos recursos humanos e dos outros recursos, nova divisão das responsabilidades e novas políticas de imputabilidade. 


\section{A RelaçÃo COM A funçÃo}

\section{UM PAPEL PLURAL}

A exemplo de vários estudos realizados em diversos países europeus (BARRÈRE, 2006; BOISSINOT, 2005; DUPRIEZ, 2002; OSBORN, 2002), os dados de nossa pesquisa indicam que os diretores consideram que seu trabalho envolve o exercício de várias responsabilidades e papéis.

Em primeiro lugar, no que diz respeito aos papéis que declaram exercer efetivamente no âmbito de seu trabalho (cf. coluna "papéis exercidos" na Tabela 2), mais de 96\% deles julgam muito importantes ou importantes os papéis relacionados à gestão e à administração: gerente de urgências, maestro e administrador-geral da escola. Vêm, em seguida, os papéis mais ligados à administração pedagógica (agente de mudança das políticas e práticas da escola, planejador do projeto educativo da escola, supervisor e avaliador do trabalho dos professores), bem como à gestão das relações externas ao estabelecimento (interlocutor dos pais e mediador, agente de ligação com as autoridades, de promoção da escola na comunidade). Os papéis considerados importantes com menos freqüência no exercício de seu trabalho são aqueles referentes à animação pedagógica (líder pedagógico) e à educação dos alunos. 


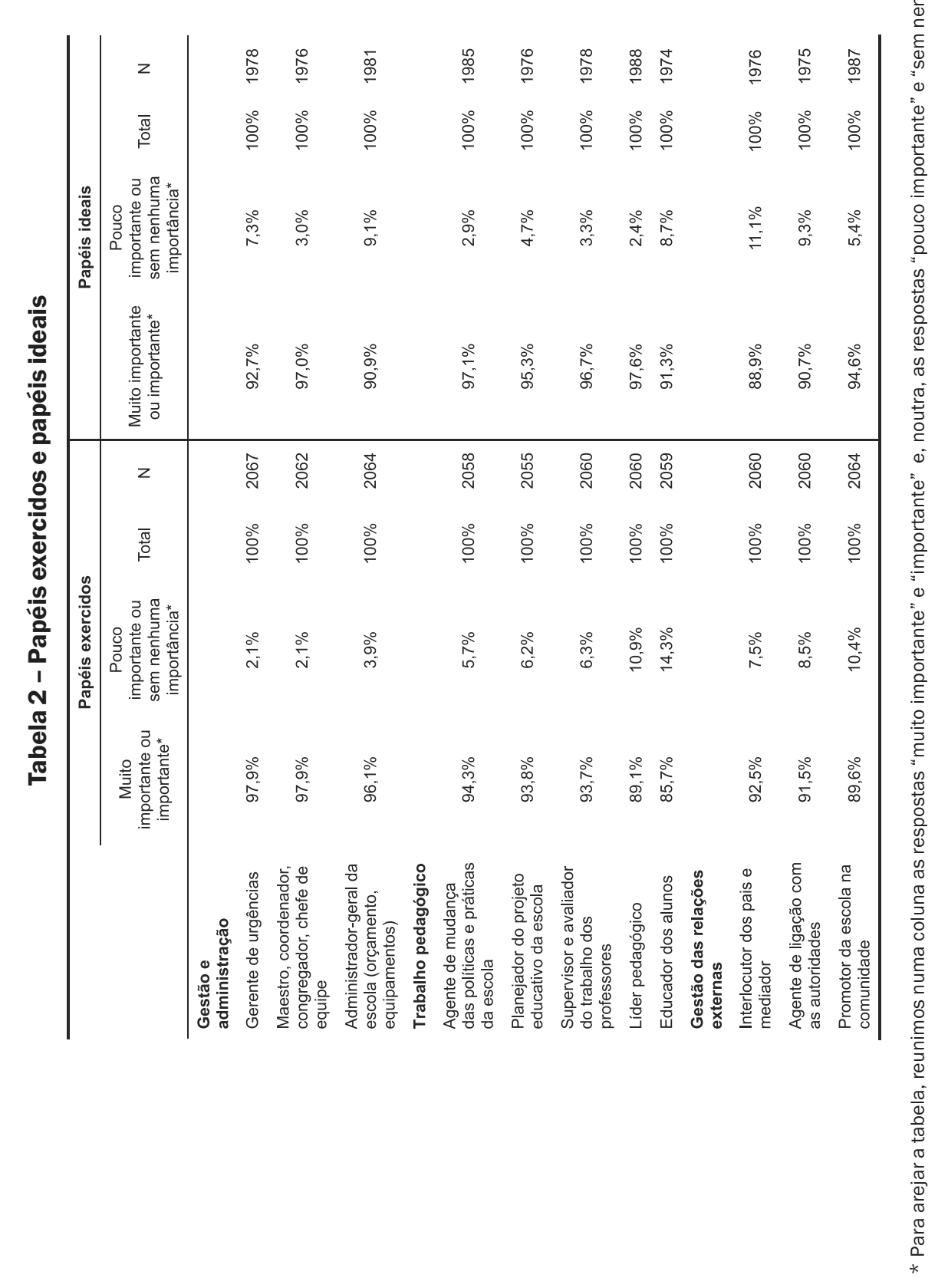


Ao observarmos os papéis que eles desejariam exercer (ver coluna "papéis ideais" da Tabela 2), vemos que a maioria dos diretores (mais de $88 \%$ ) considera que seu trabalho envolve também, idealmente, grande variedade de papéis. De modo específico, mais de $95 \%$ das pessoas questionadas valorizam os papéis relacionados ao trabalho pedagógico (líder pedagógico, agente de mudança das políticas e práticas da escola, supervisor do trabalho dos professores, planejador do projeto educativo da escola) e à coordenação (maestro). Os papéis valorizados com menos freqüência são os de interlocutor dos pais, de agente de ligação com as autoridades e de educador dos alunos. A redefinição institucional do papel dos diretores, promovida atualmente pelas políticas escolares, e que os impele a tornarem-se animadores pedagógicos e agentes de transformação educativa, parece ser considerada como um ideal pelos próprios diretores. Como ressalta Barrère, os diretores são chamados a ser "promotores de iniciativa e de dinamismo" pedagógico (especialmente através da mobilização de seu pessoal), e parecem viver essa injunção muito mais como um "princípio forte de sua realização pessoal" do que como uma imposição (BARRÈRE, 2006, p. 159).

\section{UM GRANDE NÚMERO DE RESPONSABILIDADES}

Ao examinar de maneira detalhada as diversas responsabilidades que os diretores dizem assumir (cf. a coluna "responsabilidades assumidas" da Tabela 3), percebe-se novamente que seu trabalho é altamente variado. De modo específico, observamos que a maioria dos diretores (mais de $70 \%$ ) declara realizar principalmente tarefas referentes: à administração pedagógica (elaboração do regulamento e da missão da escola, distribuição da carga horária, organização das turmas de alunos, análise das estatísticas escolares, avaliação e definição dos programas e métodos pedagógicos), à prestação de contas, à supervisão dos professores, à gestão da ordem interna (sanção disciplinar e acompanhamento dos alunos), à gestão dos recursos (distribuição e elaboração do orçamento, à gestão dos fundos gerados e dos recursos materiais) e à gestão das relações externas (sensibilização da comunidade, resolução de conflitos com as famílias, coordenação da participação dos pais, desenvolvimento de parcerias com o meio no qual a escola está inserida). Inversamente, a maioria (mais de $60 \%$ ) afirma assumir papel pouco relevante ou não ser responsável de forma alguma pelo recrutamento de alunos e de profissionais de níveis superior e técnico, nem pela avaliação do material didático. Além disso, 
boa parte dos diretores (34\% e 49\%) afirma ter pouca ou nenhuma responsabilidade em relação ao recrutamento e desenvolvimento pedagógico dos professores, à supervisão dos profissionais de níveis superior e técnico, à formação dos pais, à escolha do material didático e à coleta de fundos privados. Por outro lado, pode-se ressaltar que 62,1\% dos diretores não assumem nenhuma função de ensino.

Um estudo qualitativo realizado na França por Barrère (2006) evidencia o fato de que efetuar esse grande número de tarefas pode ser desgastante, principalmente por serem elas breves, dispersas e fragmentadas. Simultaneamente, isso é percebido pelos diretores de escola como algo estimulante, que proporciona uma "sensação exaltante de ação" e reforça seu sentimento de utilidade. Nossa pesquisa mostra, aliás, que os próprios diretores desejariam, idealmente, exercer um sem-número de tarefas (ver a coluna "responsabilidades idealizadas" da Tabela 3). De maneira geral, observamos que eles valorizam, sobretudo, responsabilidades ligadas ao trabalho pedagógico (distribuição da carga horária e atribuição das turmas, elaboração da missão e do regulamento da escola), às relações com os professores (supervisão e recrutamento dos professores) e à gestão dos recursos (distribuição e elaboração do orçamento). Inversamente, a maioria não desejaria assumir responsabilidades ligadas ao recrutamento e à seleção de alunos, à coleta de fundos privados, à avaliação do material didático e à formação pedagógica dos pais. As tarefas relacionadas com a gestão do pessoal nãodocente (supervisão e recrutamento dos profissionais de níveis superior e técnico) também são pouco valorizadas por uma parte importante dos diretores. 


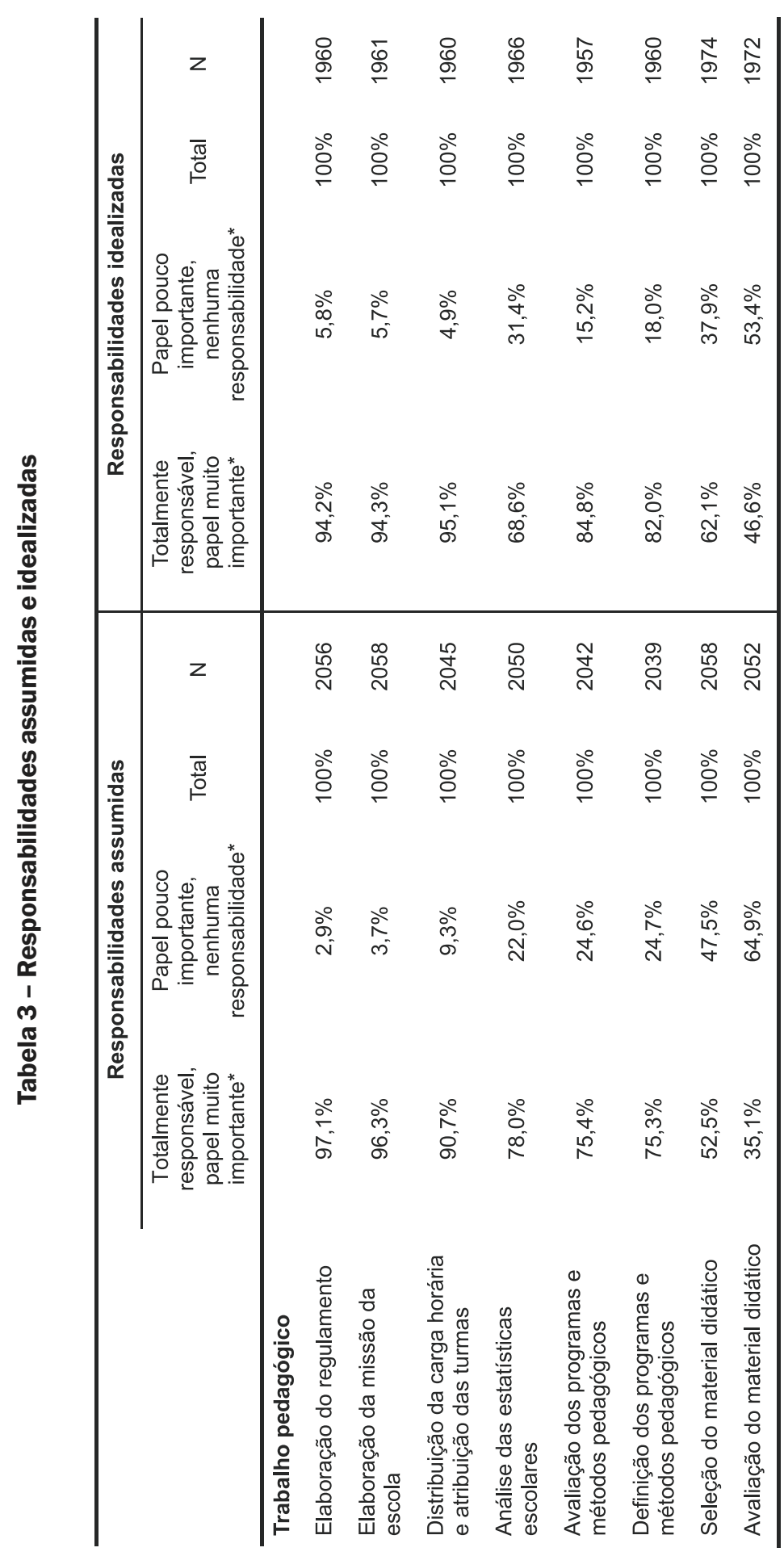




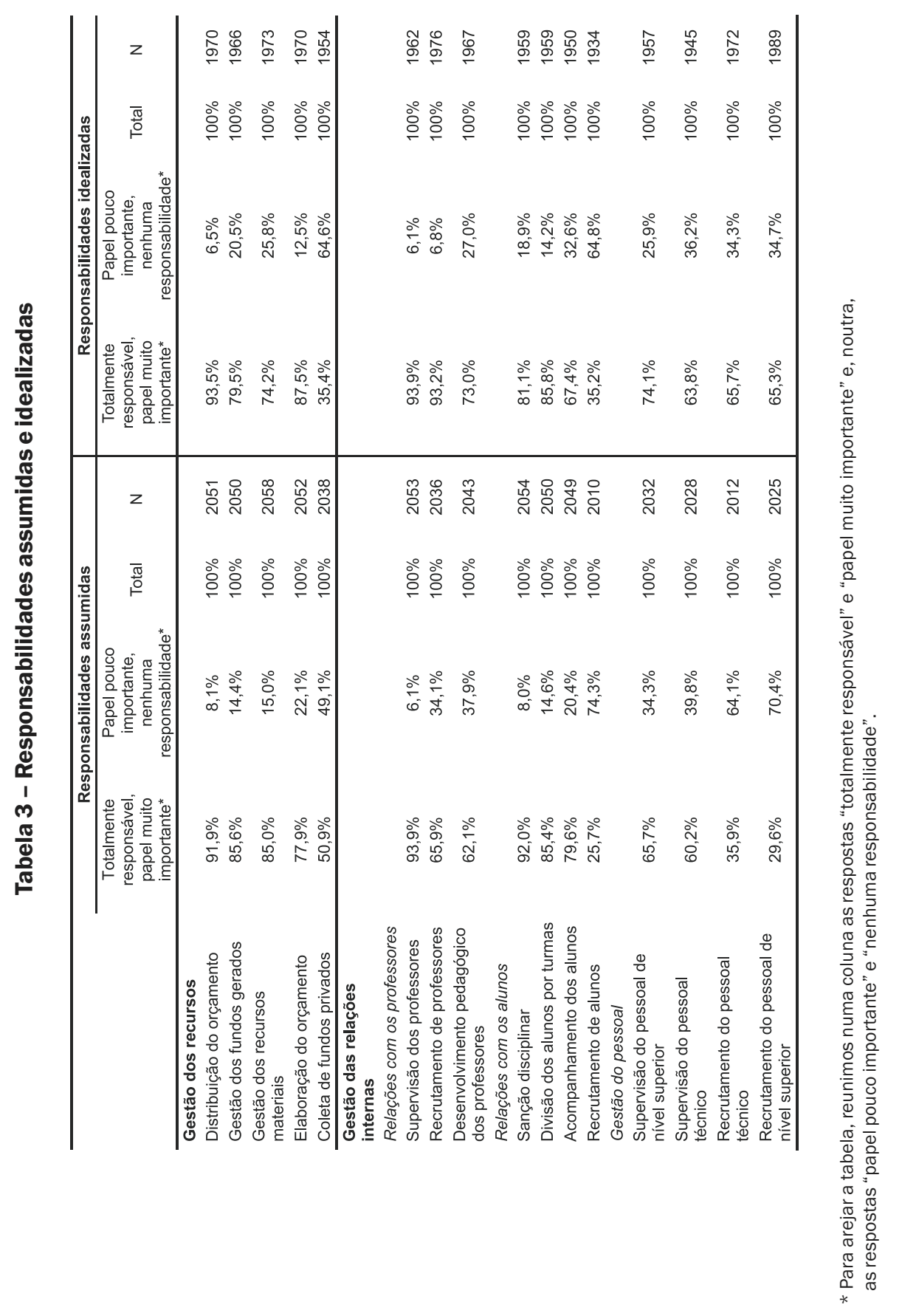




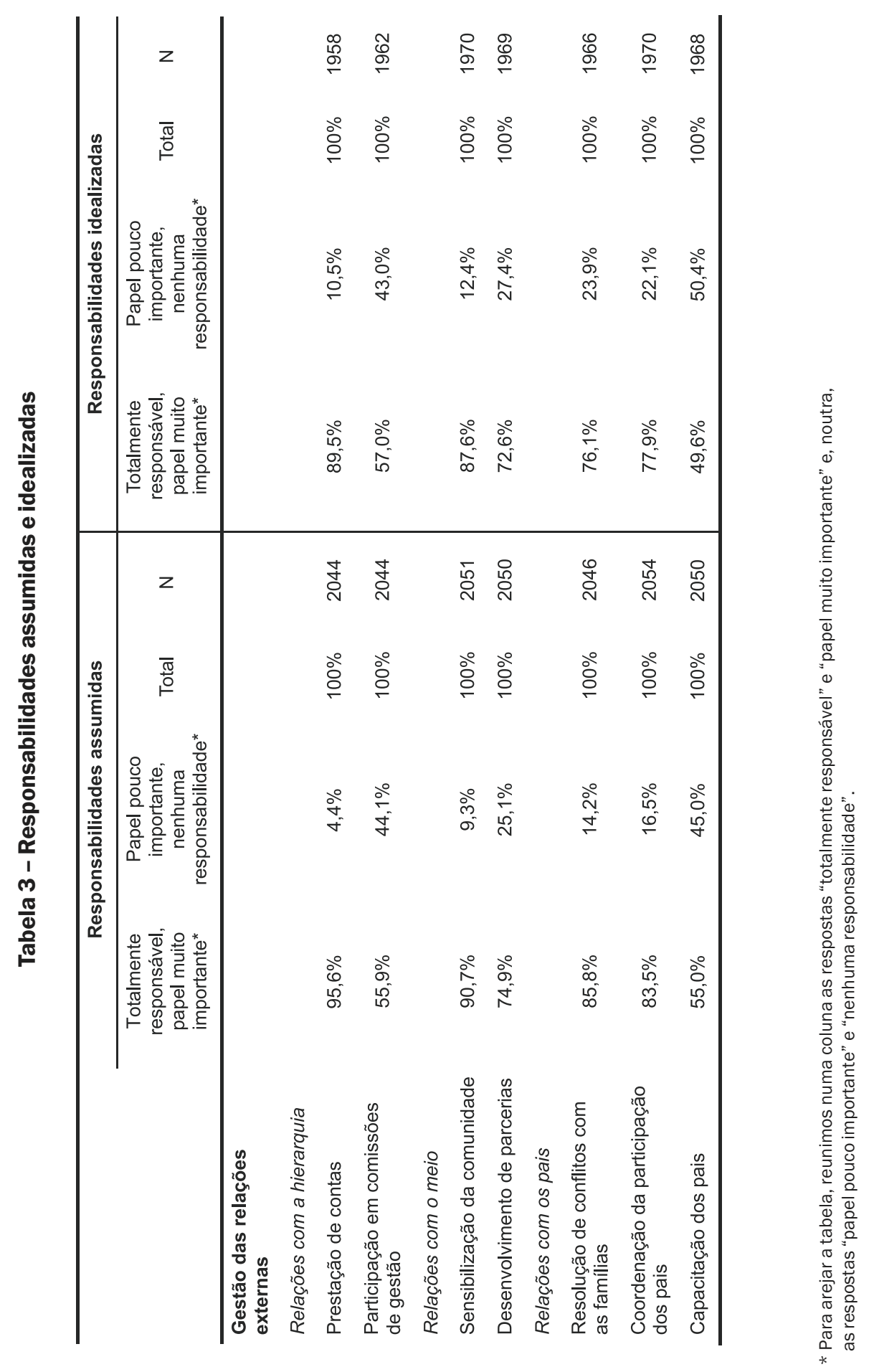

Educação em Revista, Belo Horizonte, v. 44. p. 185-208. dez. 2006 


\section{Concordâncias e tensões entre O "trabalho real” e o "trabalho ideal"}

Ao compararmos as concepções ideais dos diretores, no que se refere à sua função e às tarefas exercidas efetivamente, observamos, inicialmente, grande concordância. Com efeito, a maioria dos diretores que dizem assumir uma responsabilidade ou um papel declara também desejar cumprilo idealmente, assim como a maioria que diz não assumir uma responsabilidade ou um papel declara também não desejar cumpri-lo idealmente. Podemos supor, então, que a maioria dos diretores faz o que gostaria de fazer. Observamos, no entanto, que um número maior de diretores gostaria de ter responsabilidades relacionadas com a gestão do pessoal docente (especialmente o recrutamento), o trabalho pedagógico (definição e avaliação dos programas pedagógicos, seleção e avaliação do material didático, papel de líder pedagógico) e a gestão do orçamento. Inversamente, um número maior de diretores desejaria idealmente ter menos responsabilidades relativas à gestão das relações com os alunos (acompanhamento dos alunos e sanção disciplinar), às relações com os pais, à análise dos dados escolares, à prestação de contas e à coleta de fundos privados.

Outros estudos, em países com contextos diferentes, também evidenciaram certa tensão entre, de um lado, o trabalho administrativo e a gestão das relações externas, que os diretores devem assumir e que consideram freqüentemente ingratas ou menos nobres e, do outro, o trabalho de animação pedagógica, que eles valorizam, mas ao qual não podem dedicar todo o tempo desejado (BARRÈRE, 2006; DUPRIEZ, 2002; LECLERCQ, 2005). Os dados de nossa pesquisa sugerem também que certas tarefas prescritas pela evolução do modo de regulação escolar são "rejeitadas" por uma parte dos diretores (como a análise dos dados escolares e a prestação de contas), ao passo que outras parecem ser vistas como algo ideal (como a animação pedagógica).

\section{UMA satisfação PROfissional GLOBAL}

Apesar da complexidade de seu trabalho, nossa pesquisa mostra que a maioria dos diretores se declara totalmente ou mais satisfeita do que insatisfeita em relação à maior parte dos aspectos de sua função. De modo específico, mais de $80 \%$ se dizem satisfeitos com seu desenvolvimento profissional (87,9\%, se adicionarmos as duas primeiras posições da escala), 
com o apoio de seus superiores $(84,6 \%)$, com sua imputabilidade $(82,3 \%)$ e com sua autonomia profissional $(81,0 \%)$. Contudo, eles estão mais divididos no que diz respeito à sua remuneração $(52,6 \%$ se dizem satisfeitos, contra 47,4\% de insatisfeitos), e a maioria está insatisfeita (totalmente ou mais insatisfeita do que satisfeita) com relação à sua carga de trabalho $(53,3 \%)$ e à incidência disso em sua vida familiar $(63,9 \%)$.

Tabela 4 - Satisfação profissional

\begin{tabular}{lcccccc}
\hline & $\begin{array}{c}\text { Totalmente } \\
\text { satisfeito }\end{array}$ & $\begin{array}{c}\text { Mais satisfeito } \\
\text { do que } \\
\text { insatisfeito }\end{array}$ & $\begin{array}{c}\text { Mais insatisfeito do } \\
\text { que satisfeito }\end{array}$ & $\begin{array}{c}\text { Totalmente } \\
\text { insatisfeito }\end{array}$ & Total & N \\
\hline Desenvolvimento profissional & $29,6 \%$ & $58,6 \%$ & $10,0 \%$ & $1,8 \%$ & $100 \%$ & 2082 \\
Apoio dos superiores & $43,3 \%$ & $42,7 \%$ & $10,5 \%$ & $3,5 \%$ & $100 \%$ & 2073 \\
Imputabilidade & $19,2 \%$ & $63,7 \%$ & $14,3 \%$ & $2,8 \%$ & $100 \%$ & 2074 \\
Autonomia profissional & $23,5 \%$ & $58,0 \%$ & $15,3 \%$ & $3,2 \%$ & $100 \%$ & 2077 \\
Reconhecimento da função & $15,4 \%$ & $44,8 \%$ & $29,1 \%$ & $10,7 \%$ & $100 \%$ & 2075 \\
Enquadramento do trabalho através de & $7,0 \%$ & $54,6 \%$ & $30,9 \%$ & $7,5 \%$ & $100 \%$ & 2063 \\
normas jurídicas & $11,9 \%$ & $41,0 \%$ & $32,8 \%$ & $14,4 \%$ & $100 \%$ & 2074 \\
Remuneração & $9,5 \%$ & $37,3 \%$ & $36,8 \%$ & $16,3 \%$ & $100 \%$ & 2080 \\
Carga de trabalho & $6,2 \%$ & $30,5 \%$ & $45,5 \%$ & $17,8 \%$ & $100 \%$ & 2072 \\
\hline Incidência do trabalho na vida familiar & & & & &
\end{tabular}

A sobrecarga de trabalho e a relação problemática entre vida privada e profissional são freqüentemente ressaltadas na literatura sobre a função de diretor (BARRÈRE, 2006; BOUCHAMMA, 2004; CORRIVEAU, 2004; KING E PEART, 1992; LECLERCQ, 2005; OSBORN, 2002), e isso é bastante compreensível se considerarmos o grande número de tarefas que os diretores têm de cumprir. A satisfação profissional global por eles demonstrada, entretanto, pode parecer mais surpreendente, à primeira vista, se a compararmos com a insatisfação profissional expressa, em geral, pelos professores (CATTONAR, 2006b). Todavia, a satisfação profissional pode ser compreendida com base nas expectativas em relação à profissão e nas motivações profissionais que influem na escolha da carreira (MICHEL, 1998). ${ }^{11}$ Baseando-nos em outros estudos que analisaram os motivos que norteiam a escolha de abandonar o ensino para iniciar a

11 Precisemos que os dados de nossa pesquisa mostram que há uma fraca correlação entre a satisfação profissional dos diretores no tocante aos diversos aspectos de sua função e os papéis e responsabilidades que eles dizem assumir. 
carreira de diretor, poderíamos, então, supor que a satisfação profissional desse setor está ligada ao exercício de responsabilidades e à variedade de suas tarefas, apectos da função freqüentemente evocados entre as motivações profissionais mais importantes (BARRÈRE, 2006; CACOUAULT-BITAUD, 1998). Assim, segundo Barrère, "o otimismo profissional dos diretores pode ser compreendido na interseção entre um trabalho diversificado e múltiplo - no qual cada novo dia pode trazer certo número de soluções de problemas ou de intervenções relacionais e a representação de uma melhoria possível do estabelecimento que muito lhes deve" (BARRÈRE, 2006, p. 158).

\section{OS Determinantes do tRABalHo E DA EXPERIÊNCIA DOS DIRETORES}

Além das tendências comuns que acabamos de expor, e sem poder entrar nos detalhes da análise, gostaríamos, entretanto, de sublinhar que nossa pesquisa mostra que o exercício da função e a experiência variam de acordo com diversas características do contexto no qual os diretores atuam. ${ }^{12}$ Em primeiro lugar, diferem conforme os contextos sociopolítico e institucional (as províncias). Assim, são os diretores de Alberta, de Ontário, da Colúmbia Britânica e do Quebec que declaram com mais freqüência assumir o recrutamento dos alunos, o que é compreensível se considerarmos que também são os diretores dessas quatro províncias que com mais freqüência acham importante o impacto do aumento da competição entre as escolas. Contudo, de maneira muito esquemática, os dados da pesquisa indicam que os diretores do Quebec distinguem-se dos das outras províncias na medida em que afirmam com mais freqüência exercer tarefas ligadas à gestão do orçamento e à administração, ao passo que os das outras províncias declaram com mais freqüência realizar tarefas ligadas ao ensino e à educação dos alunos, à administração pedagógica, à supervisão dos professores e à promoção de suas escolas na comunidade. Essas diferenças ainda precisam ser exploradas com profundidade para serem bem compreendidas, através do cotejo com as políticas escolares, as características do sistema educacional e a história da profissão específica a cada uma delas.

12 Mas as representações ideais das responsabilidades ou dos papéis variam pouco de acordo com o contexto de trabalho. 
A experiência profissional dos diretores varia, em seguida, conforme o nível de ensino e a localização urbana ou rural de sua escola. Por exemplo, os diretores que lecionam se encontram com mais freqüência nas escolas mistas (onde existe ensino primário e secundário ao mesmo tempo) e rurais; o recrutamento de alunos é mais realizado pelos diretores das escolas secundárias e urbanas; a educação, a sanção disciplinar e a gestão das relações com os pais, pelos diretores das escolas primárias. Já as atitudes escolares e os comportamentos dos alunos parecem desempenhar papel importante na satisfação profissional dos diretores. Assim, quanto mais eles afirmam enfrentar diversos problemas com os alunos (apatia, atraso, comportamento insolente, absenteísmo etc.), mais tendem a declarar-se insatisfeitos em relação a vários aspectos de sua função.

A análise mostra, entretanto, que a maneira de exercer, conceber e viver a função varia muito pouco segundo o perfil socioprofissional dos diretores (gênero, idade, tempo de trabalho, nível e campo de estudo). Observa-se apenas que os homens declaram com mais freqüência assumir e valorizar as tarefas de gestão do pessoal (recrutamento e supervisão) e de gestão do orçamento do que as mulheres. O teor do trabalho dos diretores parece, portanto, estar ligado, antes de tudo, às contingências contextuais.

\section{Que reestruturação da função de diretor?}

Em resumo, nossa pesquisa mostra que os diretores encontram-se confrontados hoje com inúmeras transformações, as quais, segundo eles, têm impactos importantes em sua função e no funcionamento da escola. Entretanto, embora apontem várias repercussões negativas das transformações escolares, parecem permanecer otimistas em relação aos efeitos positivos que elas terão sobre as escolas. Além disso, exceto no que se refere à sua carga de trabalho, expressam grande satisfação com relação a vários aspectos de sua função.

Finalmente, poderíamos interrogar-nos em que medida os dados de nossa pesquisa permitem concluir que houve uma reestrutruração da função de diretor provocada pelas recentes transformações no modo de regulação escolar. Como vimos, quando a pergunta é feita diretamente aos diretores, a maioria afirma que as transformações escolares tiveram um impacto sobre o teor e sobre sua carga de trabalho (aumento da carga de trabalho, modificação na sua maneira de gerir, maior interesse pelas 
relações com o meio no qual a escola está inserida), bem como sobre o desenvolvimento de suas competências (exigência de novas capacidades de adaptação). Seria possível, então, supor que as numerosas responsabilidades que eles dizem exercer vêm acompanhadas de uma complexificação de seu papel. Também poderíamos levantar a hipótese de que as recentes transformações escolares ocasionam um aumento na supervisão dos professores pelos diretores, e um aumento no envolvimento destes com as relações externas à escola, na medida em que as correlações entre a percepção das transformações escolares e o trabalho realizado ou idealizado pelos diretores se referem com mais freqüência às tarefas ligadas à supervisão dos professores, à gestão das relações com os pais, ao desenvolvimento de parcerias com o meio no qual a escola está inserida e à promoção da escola na comunidade. ${ }^{13}$ Essas hipóteses precisariam, contudo, ser verificadas com mais seriedade, especialmente comparando nossos dados com outros provenientes de estudos mais antigos.

\section{Referências Bibliográficas}

BARRÈRE, A. Sociologie des chefs d'établissement. Les managers de la République. Paris: Presses Universitaires de France, 2006.

BEN JAAFAR, S.; ANDERSON, S. E. Accountability in education: trends in Canada from 1990-2003. Paper presented at the Annual Meeting of the Canadian Society for Studies. Education, Winnipeg, 29 mai-1er juin 2004.

BERGERON, D.; MASSE, D.; RATHE, J.-P. Réforme, décentralisation et professionnalisation des chefs d'établissement au Québec. Politiques d'Éducation et de Formation. Analyses et Comparaisons Internationales, 13 (1), 2005.

BERNARD, P.; SAINT-ARNAUD, S. Du pareil au même? La position des quatre principales provinces canadiennes dans l'univers des régimes providentiels. Cabiers Canadiens de Sociologie, 29 (2), 2004.

BOISSINOT, M.-M. Chefs d'établissement en France: une situation paradoxale au centre de tensions multiples. Politiques d'Éducation et de Formation. Analyses et Comparaisons Internationales, 13 (1), 2005.

13 Assim, quanto mais os diretores acham importante o impacto das diversas transformações propostas (em especial, a diminuição dos recursos humanos e dos outros recursos, as novas abordagens educativas, a diversificação cultural da clientela escolar, as novas políticas de imputabilidade, a nova divisão das responsabilidades entre as instâncias centrais e locais), mais eles declaram ser e desejar ser responsáveis pela supervisão dos professores, pela formação dos pais, pelo desenvolvimento de parcerias com o meio e pela promoção da escola na comunidade. 
BOUCHAMMA, Y. Gestion de l'éducation et construction identitaire sur le plan professionnel. Education et Francophonie, XXXII (2), 2004.

BRASSARD, A.; CLOUTIER, M.; DE SAEDELEER, S.; CORRIVEAU, L.; FORTIN, R.; GELINAS, A.; SAVOIE-ZAJC, L. Rapport à l'activité éducative et identité professionnelle chez les directeurs d'établissement des ordres d'enseignement préscolaire et primaire. Revue des Sciences de l'Éducation, XXX (3), 2004.

CACOUAULT-BITAUD, M. Les personnels de direction du second degré dans trois académies: déterminants d'accès aux fonctions et représentations du rôle. In: BOURDONCLE, R.; DEMAILLY, L. (Ed.). Les professions de l'éducation et de la formation. Paris: Presses Universitaires du Septentrion, 1998. p. 339-350.

CATTONAR, B. Les identités professionnelles enseignantes. Ebauche d'un cadre d'analyse. Les Cahiers de Recherche du Girsef, Louvain-la-Neuve, n. 10, 2001.

CATTONAR, B. Convergence et diversité de l'identité professionnelle des enseignants du secondaire en Communauté française de Belgique. Tensions entre le vrai travail et le sale boulot. Education et Francophonie, 2006 a.

CATTONAR, B. Comment les enseignants du secondaire conçoivent-ils et viventils leur métier? In: CHAPPELLE, G.; MEURET, D. Améliorer l'école. Paris: Presses Universitaires de France, 2006b.

CORCUFF, P. Les nouvelles sociologies. Constructions de la réalité sociales. Paris: Nathan Université, 1995.

CORRIVEAU, L. Identification professionnelle ou suridentification à la profession? Éducation et Francophonie, XXXII (2), 2004.

DUBAR, C. La socialisation. Construction des identités sociales et professionnelles. Paris: Armand Colin, 1996.

DUPRIEZ, V. Entre tradition et transformations, que révèle l'analyse des établissements scolaires? In: MAROY, C. (Dir.). Les écoles d'enseignement secondaire et leurs enseignants. Bruxelles: De Boeck Université, 2002. p. 55-90.

La transformation du métier de chef d'établissement en Communauté française de Belgique. Politiques d'Éducation et de Formation. Analyse et Comparaisons Internationales, 13 (1), 2005.

DUTERCQ, Y. Les nouveaux pouvoirs des chefs d'établissements. In: CHAPELlE, G.; MEURET, D. Améliorer l'école. Paris: Presses Universitaires de France, 2006. p. 141-152.

KING, A. J. C.; PEART, M. J. Le personnel enseignant au Canada. Travail et qualité de vie. Ottawa: Fédération canadienne des enseignantes et des enseignants/ Groupe d'évaluation des programmes sociaux/Université Queen's à Kington, 1992. 
LECLERCQ, J.-M. Perspective internationale: quelle direction pour les établissements scolaires? Politiques d'Éducation et de Formation. Analyse et Comparaisons Internationales, 13 (1), 2005.

LESSARD, C.; BRASSARD, A. La "gouvernance" de l'éducation au Canada: tendances et significations. Education et sociétés, 2007. (No prelo).

LESSARD, C.; GRIMMETT, P. Canadian education policy trends, the professionnal lives of teachers and the democratic redefinition of public education. Document de présentation d'une demande de soutien d'un réseau, CRSH, 2004.

MAROY, C.; DUPRIEZ, V. La régulation dans les systèmes scolaires. Proposition théorique et analyse du cadre structurel en Belgique francophone. Revue Française de Pédagogie, n. 13, 2000.

MICHEL, S. Motivation et implications professionnelles. In: COSTER DE, M.; PICHAULT, F. (Dir.). Traité de sociologie du travail. Bruxelles: De Boeck Université, 1998. p. 403-421.

OSBORN, M. Le nouveau rôle des chefs d'établissements: le cas de l'Angleterre. Politiques d'Éducation et de Formation, 5 (2), 2002.

PELAGE, A. Les transformations de la fonction de proviseur. In: BOURDONCLE, R.; DEMAILLY, L. (Ed.). Les professions de l'éducation et de la formation. Paris: Presses Universitaires du Septentrion, 1998. p. 75-89.

La redéfinition du métier de chef d'établissement secondaire:

changement statutaire, construction de l'engagement professionnel et épreuves pratiques. Revue Française de Pédagogie, n. 145, 2003.

(Tradução: Francisco Pereira de Lima)

Recebido em: 30/09/2006

Aprovado em: 06/11/2006 